\title{
PENINGKATAN KETERAMPILAN MENULIS PARAGRAF ARGUMENTASI DENGAN METODE TOPI PEMIKIRAN (SIX THINKING HATS) PADA SISWA KELAS X SMA GUPPI SAMATA
}

\author{
Indramini \\ Universitas Muhammadiyah Makassar \\ email : indramini@gmail.com
}

\begin{abstract}
Abstrak
Penelitian ini dilatarbelakangi oleh masalah rendahnya keterampilan siswa dalam menulis paragraf argumentasi. Jenis Penelitian ini adalah penelitian tindakan kelas (PTK). Adapun tujuan dari penelitian ini yaitu untuk meningkatkan keterampilan menulis paragraf argumentasi dengan metode Topi Pemikiran (Six Thinking Hats) pada siswa kelas X SMA Guppi Samata. Subjek penelitian ini adalah siswa kelas X-A yang terdiri atas 31 siswa. Teknik pengumpulan data yang digunakan dalam penelitian ini berupa, tes, observasi, analisis dokumen, dokumentasi dan wawancara serta format penilaian. Hasil penelitian ini menunjukkan bahwa keterampilan menulis paragraf argumentasi dengan metode Topi Pemikiran (Six Thinking Hats) pada siswa kelas X A SMA Guppi Samata. Peningkatan keterampilan menulis paragraf argumentasi tampak pada kualitas proses kualitas hasil. Peningkatan proses pada akhirnya berdampak positif pada peningkatan produk pratindakan sampai siklus II. Nilai Rata-rata skor pada pratindakan diperoleh 61,03, nilai rata-rata skor pada siklus I diperoleh 78,83 dan nilai rata-rata skor pada siklus II diperoleh 84,0 . Kenaikan skor rata-rata mulai dari pratindakan hingga siklus II diperoleh 22,97. Secara keseluruhan semua aspek dari kriteria menulis paragraf argumentasi mengalami peningkatan yang cukup signifikasn, yaitu dari aspek isi, organisasi isi, kosakata, penggunaan bahasa dan mekanik.
\end{abstract}

Kata Kunci: Menulis, Paragraf Argumentasi, Metode Topi Pemikiran (Six Thinkin Hats)

\begin{abstract}
This research is motivated by the problem of low student skills in writing paragraphs argument. This research is a type of class action (PTK). The purpose of this research is to improve the writing skills of argumentation paragraph Thinking Hats method (Six Thinking Hats) in class X SMA Guppi Samata. The subjects were students XA class consisting of 31 students. Data collection techniques used in this study are, tests, observation, document analysis, documentation and interviews and assessment format. The results of this study indicate that the writing skills of argumentation paragraph Thinking Hats method (Six Thinking Hats) on XA grade high school students Guppi Samata. Improved writing skills paragraph argument looks at the quality of the quality of the results. Improved process ultimately have a positive impact on improving product pratindakan until the second cycle. Value average score on pratindakan obtained 61.03, the average value of the score in the first cycle obtained 78.83 and the average value of the score in the second cycle was obtained 84.0. The increase in average scores ranging from pratindakan until the second cycle obtained 22.97. Overall all the aspects of writing paragraphs criteria argumentation has increased signifikasn, from the aspect of content, organization of content, vocabulary, language usage, and mechanics.
\end{abstract}

Keywords: Writing, Paragraph argument, Thinking Hats method (Six Thinking Hats)

\section{PENDAHULUAN}

Bahasa merupakan alat komunikasi yang utama bagi manusia dengan sesamanya. Dalam berbahasa, manusia membutuhkan suatu keterampilan agar dapat berkomunikasi dengan lancar dan benar. Keterampilan berbahasa memiliki empat komponen, yaitu menyimak, berbicara, membaca, dan menulis.Menulis merupakan suatu keterampilan berbahasa yang dipergunakan untuk berkomunikasi secara tidak langsung atau tanpa tatap muka.
Menulis merupakan suatu keterampilan berbahasa yang dipergunakan untuk berkomunikasi secara tidak langsung atau tanpa tatap muka. Tidak hanya itu, menulis meliputi suatu kegiatan yang dapat menghasilkan sebuah karya yang mampu menggambarkan gagasan dan perasaan hati. Jadi, keterampilan menulis sebagai salah satu keterampilan berbahasa atau kegiatan yang produktif dan merupakan bagian yang tidak pernah terpisahkan dalam seluruh proses pembelajaran yang dialami siswa selama menuntut ilmu 
disekolah. Menulis memerlukan keahlian. Oleh karena itu, diperlukan latihan-latihan yang berkelanjutan.

Menulis yang dimaksud di sini tentu saja bukan hanya sekedar menuliskan huruf-huruf di atas kertas, akan tetapi menulis dalam arti luas. Berikut ini pengertian menulis menurut beberapa para ahli.

Kamus Besar Bahasa Indonesia (Depdiknas, 2012: 1497) mengartikan bahwa menulis adalah melahirkan pikiran atau perasaan (seperti mengarang, membuat surat) dengan tulisan. Melalui kegiatan menulis, seseorang dapat menuangkan ide-isenya atau meluapkan isi perasaanya. Dengan demikian, menulis merupakan suatu cara mengekspresikan pikiran atau perasaan dalam bentuk tulisan

Menurut Tarigan dalam Munirah (1982: 23), menulis adalah salah satu keterampilan berbahasa yang dipergunakan untuk berkomunikasi secara tidak langsung, tidak secara tatap muka dengan orang lain.

Dari beberapa uraian diatas, dapat disimpulkan bahwa menulis merupakan suatu bentuk komunikasi yang tidak langsung untuk menyampaikan gagasan penulis kepada pembaca dengan menggunakan bahasa sebagai media penyampaiannya. Tulisan yang bermutu selalu berpangkal pada pemikiran yang tepat dan jelas, hal itu akan tercermin dalam isi, pemilihan kata dan tata susunan dari seluruh uraian tersebut.

Tujuan Menulis

Hugo Hartig (dalam Taringan 1984) membagai tujuan penulisan, diantaranya sebagai berikut;

a. Tujuan penugasan. Pada tujuan ini, penulis menulis sesuatu karena ditugaskan bukan karena kemauan sendiri. Misalnya: Siswa ditugaskan merangkum, sekretaris, dan lainlain.

b. Tujuan altruistik. Penulis bertujuan untuk menyenangkan para pembaca, menghindarkan kedukaan, ingin menolong para pembaca memahami, menghargai perasaan serta ingin membuat hidup para pembaca lebih mudah dan lebih menyenangkan dari hasil karyanya.

c. Tujuan persuasif. Penulis bertujuan meyakinkan para pembaca akan gagasan dan kebenaran yang diutarakan.

Ciri-ciri Tulisan yang Baik. a. Tulisan yang baik mencerminkan kemampuan sang penulis menyusun bahan-bahan menjadi satu kesatuan yang utuh.

b. Tulisan yang baik mencerminkan kemampuan sang penulis untuk menulis dengan jelas dan tidak samar-samar, memanfaatkan struktur kalimat bahasa dengan contoh sehingga maknanya sesuai

Pengertian Paragraf

Kamus Besar Bahasa Indonesia (Depdiknas, 2012: 1020) mengartikan paragraf adalah bagian bab dalam suatu karangan yang biasanya mengandung satu ide pokok dan penulisannyadimulai dengan garis baru.

Menurut Muchlison dalam Munirah (1992: 304), paragraf adalah sebuah kalimat atau gabungan dari bebrapa kalimat yang hanya mengandung satu ide atau satu gagasan serta satu pokok pikiran.

Adapun syarat-syarat pembentukan paragraf menurut Keraf dalam Munirah (1980) yaitu kesatuan, kepaduan, dan kelengkapan.

Hakikat Paragraf Argumentasi

Kesesuaian argumen dalam karangan argumentasi sangat diperlukan. Pada hakikatnya karangan argumentasi berisi ide-ide yang dapat memperkuat pernyataan. Ide-ide dapat berupa data ataupun fakta. Tulisan argumentasi harus mengandung kebenaran untuk mengubah sikap dan keyakinan orang mengenai topik yang diargumentasikan.

Ciri-Ciri Paragraf Argumentasi

a. Ada pernyataan, ide atau pendapat yang dikemukakan penulisnya untuk meyakinkan pembaca.

b. Ada alasan, data atau fakta yang mendukung.

c. Penutup beris kesimpulan.

d. Penjelasan dalam paragraf di susun atau disampaikan secara logis.

Struktur Tulisan Argumentasi

Ada tiga bagian jika dilihat dari struktur tulisan arguemntasi yaitu;

a. Pendahuluan. Penulis paragraf argumentasi harus yakin bahwa maksud suatu bagian pendahuluan adalah tidak lain untuk menarik dan memusatkan perhatian pembaca kepada argumen-argumen yang disampaikannya.

b. Tubuh atau isi argumen. bertujuan untuk membuktikan kebenaran yang akan disampaikan dalam paragraf argumentasi sehingga kesimpulan yang akan dicapai juga benar. 
c. Kesimpulan. Penulis harus menjaga agar apa yang disimpulkan tetap mengacu pada tujuan dan menyegarkan kembali ingatan pembaca tentang apa yang telah dicapai dan dapat diterima pembaca sebagai suatu pernyataan yang logis.

Metode Topi Pemikiran (Six Thinking Hats)

Dalam pembelajaran, metode adalah perancangan lingkungan belajar dimana siswa dan guru terlibat selama proses pembelaran berlangsung.

Six Thinking Hats merupakan sebuah metode yang diciptakan oleh Dr.Edward de Bono, seorang pakar psikologi dan konsultan kemahiran Malta. Seperti namanya Six Thinking Hats merupakan metode berfikir yang direpresentasikan dengan enam buah topi dengan warna yang berbeda (Putih, Kuning, Hitam, Merah, Hijau, Biru) yang melambangkan peran masing-masing warna topi tersebut. Penggunaan istilah topi dan warna tersebut tentu membuat metode ini lebih mudah dipahami dan diterapkan.

\section{METODE PENELITIAN}

Jenis penelitian ini adalah Penelitian Tindakan Kelas (PTK). Atau (classroom action research) yang dilaksanakan dalam bentuk siklus. Menurut Burns (melalui Madya, 2006: 9), Penelitian tindakan kelas merupakan penerapan penemuan fakta pada pemecahan masalah dalam situasi sosial dengan pandangan untuk meningkatkan kualitas tindakan yang dilakukan di dalamnya

Prosedur Penelitian

Rancangan penelitian tindakan kelas yang akan dilaksanakan terdiri atas dua siklus, yakni siklus pertama dan siklus kedua.
Instrumen Penelitian

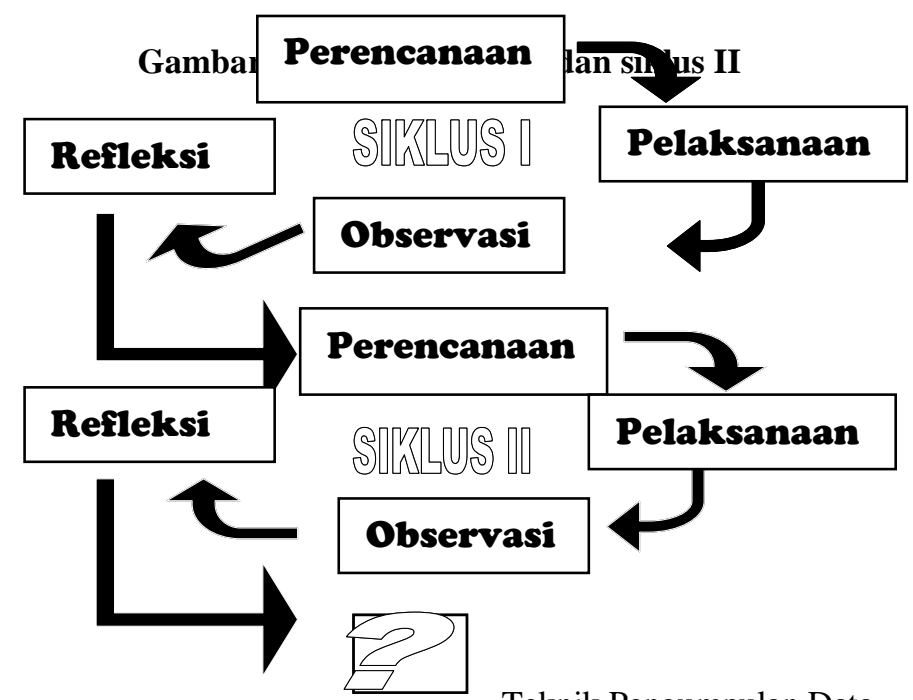

Instrumen penelitian adalah alat-alat yang mendukung proses pelaksanaan dalam peneliian. Instrumen penelitian yang peneliti gunakan dalam penelitian ini adalah sebagai berikut :

1) Instumen pembelajaran, yang digunakan peneliti sebagai acuan dalam proses belajarmengajar adalah Rencana Program Pembelajaran (RPP) yaitu berupa satuan pembelajaran yang dijadikan acuan dalam Kegiatan Belajar-Mengajar (KBM) serta Buku Paket Bahasa Indonesia Kelas X SMA.

2) Instrumen pengumpulan data yang digunakan peneliti yaitu berupa lembar angket, tes menulis, observasi, analisis dokumen dan wawancara.
Teknik Pengumpulan Data

Teknik pengumpulan data yang dilakukan dalam penelitian ini adalah sebagai berikut :

1) Tes

Tes merupakan pemberian sejumlah pertanyaan untuk mengukur kemampuan siswa dalam menulis paragraf argumentasi baik sebelum dilaksanakan tindakan maupun setelak dilaksanakan tindakan.

2) Observasi

Observasi adalah penilaian yang dilakukan melalui pengamatan terhadap peserta didik sela,a pembelajaran berlangsung.

3) Analisis Dokumen 
Analisis dokumen yang berupa lembar catatan pekerjaan siswa dilakukan untuk memperoleh data.

4) Wawancara

Wawancara dilakukan setelah kegiatan pembelajaran berlangsung. Wawancara dilakukan secara bebas, dilakukan untuk mengunggap data dan memperoleh gambaran mengenai kesan dan esan siswa selama belajar menulis paragraf argumentasi.

Teknik Analisis Data

1. Data Kualitatif

Data kualitatif berupa peningkatan wawasan, pengetahuan dan pengamalan siswa dalam menulis

\section{HASIL PENELITIAN DAN PEMBAHASAN}

Skor Hasil Menulis Paragraf Argumentasi Siswa dari Pratindakan, siklus I dan siklus II

\begin{tabular}{|c|c|c|c|c|c|c|}
\hline \multirow{2}{*}{ No } & \multirow{2}{*}{ Subjek } & \multicolumn{5}{|c|}{ Kompetensi Siswa dalam Menulis } \\
\hline & & Pratindakan & Selisih & Siklus I & Selisih & Siklus II \\
\hline 1. & S1 & 65 & 14 & 79 & 2 & 81 \\
\hline 2. & S2 & 75 & 7 & 82 & 5 & 87 \\
\hline 3. & S3 & 51 & 27 & 78 & 2 & 80 \\
\hline 4. & S4 & 38 & 35 & 73 & 12 & 85 \\
\hline 5. & S5 & 75 & 5 & 80 & 6 & 86 \\
\hline 6. & S6 & 75 & 6 & 81 & 4 & 85 \\
\hline 7. & S7 & 72 & 6 & 78 & 7 & 85 \\
\hline 8. & S8 & 66 & 13 & 79 & 4 & 83 \\
\hline 9. & S9 & 53 & 25 & 78 & 6 & 85 \\
\hline 10. & S10 & 67 & 8 & 75 & 11 & 86 \\
\hline 11. & S11 & 52 & 25 & 77 & 3 & 80 \\
\hline 12. & S12 & 51 & 35 & 86 & 1 & 87 \\
\hline 13. & S13 & 50 & 28 & 78 & 6 & 84 \\
\hline 14. & S14 & 72 & 8 & 80 & 2 & 82 \\
\hline 15. & S15 & 60 & 20 & 80 & 4 & 84 \\
\hline 16. & S16 & 75 & 7 & 82 & 4 & 86 \\
\hline 17. & S17 & 73 & 10 & 83 & 4 & 87 \\
\hline 18. & S18 & 68 & 18 & 86 & 3 & 89 \\
\hline 19. & S19 & 50 & 25 & 75 & 1 & 76 \\
\hline 20. & S20 & 53 & 23 & 76 & 1 & 86 \\
\hline 21. & S21 & 49 & 26 & 75 & 7 & 82 \\
\hline 22. & S22 & 40 & 35 & 75 & 10 & 85 \\
\hline 23. & S23 & 52 & 26 & 78 & 7 & 85 \\
\hline 24. & S24 & 58 & 17 & 75 & 5 & 80 \\
\hline 25. & S25 & 79 & 7 & 86 & 3 & 89 \\
\hline 26. & S26 & 40 & 42 & 82 & 5 & 87 \\
\hline 27. & S27 & 76 & 2 & 78 & 8 & 86 \\
\hline 28. & S28 & 76 & 4 & 80 & 6 & 86 \\
\hline 29. & S29 & 77 & 2 & 79 & 6 & 85 \\
\hline 30. & S30 & 45 & 30 & 75 & 4 & 79 \\
\hline \multirow[t]{2}{*}{31.} & S31 & 59 & 16 & 75 & 4 & 79 \\
\hline & Total nilai & 1892 & & 2444 & & 2607 \\
\hline
\end{tabular}

paragraf argumentasi. Dianalisis dengan teknik deskiptif kualitatif.

2. Data Kuantitatif

Data kuantitatif berupa peningkatan prestasi siswa dalam penelitian tindakan kelas ini dianalisis dengan teknik analisis deskriptif kuantitatif. Data yang dianalisis meliputi hasil karya siswa berupa tulisan paragraf argumentasi yang dihasilkan pada pratindakan, siklus I dan siklus II. Data yang diperoleh melalui bentuk tes akan dianalisis secara kuantitatif, sedangkan data yang diperoleh melalui observasi dan dokumentasi akan dianalisis secara kualitatif. 


\begin{tabular}{cccc}
\hline Nilai Rata-rata & $\mathbf{6 1 , 0 3}$ & $\mathbf{7 8 , 8 3}$ & $\mathbf{8 4 , 0}$ \\
\hline Nilai tertinggi & 79 & $\mathbf{8 6}$ & $\mathbf{8 9}$ \\
\hline Nilai terendah & 38 & 73 & 76 \\
\hline
\end{tabular}

Adapun grafik Peningkatan Keterampilan Menulis Paragraf Argumentasi dengan Metode Topi Pemikiran (Six Thinking Hats)

Keterampilan menulis paragraf argumentasi dengan metode Topi Pemikiran (Six Thinking Hats) bertujuan untuk mengetahui seberapa jauh peningkatan keterampilan siswa dalam menulis paragraf argumentasi. Setelah data diperoleh dapat disimpulkan, pada pratindakan rata-rata nilai yang diperoleh adalah 61,03, saat akhir siklus I rata-rata nilai yang diperoleh adalah 78,83. Nilai tersebut masih mengalami peningkatan pada akhir siklus II menjadi 84,0.gambaran lebih jelas tentang peningkatan keterampilan menulis paragraf argumentai pada siswa kelas X A SMA Guppi Samata dapat dilihat pada grafik berikut.

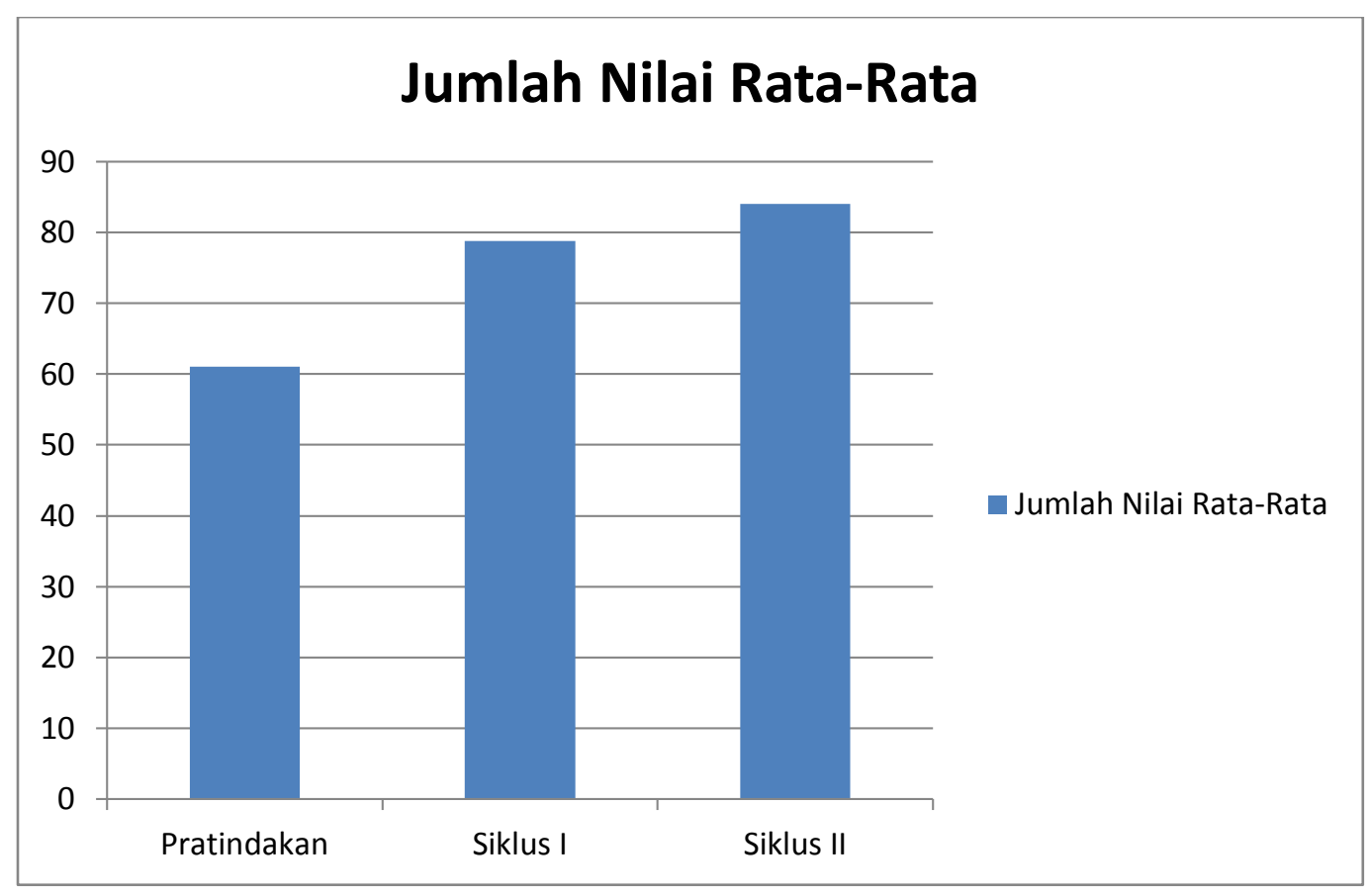

Grafik 1 : Peningkatan Nilai Rata-rata Menulis Paragraf Argumentasi

Pembahasan

1. Informasi Awal Kemampuan Siswa dalam Menulis Paragraf Argumentasi

Setelah dilakukan pratindakan, maka terlihat hasil belajar siswa yang menunjukkan bahwa kemampuan menulis paragraf argumentasi pada siswa kelas X A SMA Guppi Samata tergolong rendah. Nilairata-rata yang diperoleh adalah 61,03. Saat dilakukan pratindakan ini, siswa merasa kesulitan dalam mengungkapkan ide menjadi tulisan dan kesesuaian aspek dalam paragraf belum maksimal. Sebagaian besar dari mereka juga belum mengetahui hal-hal yang perlu diperhatikan dalam menulis paragraf argumentasi.

2. Pelaksanaan Tindakan Kelas Pembelajaran Menulis Paragraf Argumentasi dengan Metode Topi Pemikiran (Six Thinking Hats).
Pelaksanaan pembelajaran menulis paragraf argumentasi dengan metode Topi Pemikiran (Six Thinking Hats) yang telah dilaksanakan dalam dua siklus memfokuskan pada menulis paragraf argumentasi secara terstruktur. Peningkatan itu terlihat pada kualitas proses dan kualitan hasil

a. Peningkatan kualitas proses

Berdasarkan pengamatan dalam proses pembelajaran menulis paragraf argumentasi dengan metode Topi Pemikiran (Six Thinking Hats). Dari pratindakan, siklus I dan siklus II terlihat adanya kualitas pembelajaran yang baik. Kekurangan yang terdapat pada siklus I mampu ditingkatkan pada siklus II. Pembelajaran keterampilan menulis paragraf argumentasi dengan Topi Pemikiran (Six Thinking Hats).mampu membantu siswa dalam proses menulis. Siswa dapat menuangkan ide, gagasan dan menghasilkan tulisan yang baik.. 
selama proses pembelajaran peneliti memegang penan penting dalam menunjang keberhasilan siswa khususnya keterampilan menulis.

b. Peningkatan kualitas hasil peningkatan aktivitas belajar siswa berdampak positif pada peningkatan hasil pembelajaran. Peningkatan kualitas hasil menulis paragraf argumentasi dapat dilihat dai perkembangan hasil akhir kerja siswa selama dua siklus yaitu Setelah data diperoleh dapat disimpulkan, pada pratindakan rata-rata nilai yang diperoleh adalah 61,03, saat akhir siklus I rata-rata nilai yang diperoleh adalah 78,83 . Nilai tersebut masih mengalami peningkatan pada akhir siklus II menjadi 84,0.

\section{KESIMPULAN DAN SARAN}

Kesimpulan

Berdasarkan data hasil penelitian dan pembahasan dalam penelitian tindakan kelas ini, dapat disimpulkan bahwa metode Topi Pemikiran (Six Thinking Hats) dapat meningkatkan keterampilan menulis paragraf argumentasi pada siswa kelas X A SMA Guppi Samata. Saat pratindakan, rata-rata nilai yang diperoleh siswa adalah 61,03. Saat akhir siklus I, rata-rata nilai yang diperoleh siswa meningkat menjadi 78,83. Dengan demikian terjadi peningkatan sebesar 17,8 poin Nilai tersebut mengalami peningkatan kembali pada pelakanaan siklus II menjadi 84,0. Berarti antara siklus I dan siklus II mengalami peningkatan sebesar 5,17 poin.

Saran

1. Bagi guru, kreativitas guru dalam proses pembelajaran menulis paragraf argumentasi dengan metode Topi Pemikiran (Six Thinking Hats) harus lebih ditingkatkan agar siswa lebih antusias dalam pembelajaran menulis dan Bagi siswa, siswa harus lebih giat berlatih menulis agar dapat menghasilkan tulisan yang baik dan layak dipublikasikan.

3. Bagi sekolah, sekolah hendaknya memberikan kesempatan kepada siswa untuk dapat memgembangkan keterampilannya dalam kegiatan menulis, khsusnya menulis paragraf argumentasi Hal ini dapat dilakukan seperti melaksanakan perlombaan antar kelas.

4. Bagi peneliti lain, hendaknya pembelajaran menulis terutama menulis paragraf argumentasi dilakukan lebih inovatif dan dengan waktu yang memadai dan terus memacu siswa dengan

menggunakanberbagai metode agar

mengahsilakn tulisan yang lebih baik.

\section{REFERENSI}

Abi Sofyan Giffari. 2013. Six Thinking Hats. (Online) netsains.net/013/10/six-thinkinghats, Diakses 03 Maret 2014, Pukul 09.55

Akhadiah, Sabarti dkk. 2001. Pembinaan Kemampuan Menulis Bahasa Indonesia. Jakarta: Erlangga

Arikunto, Suharsimi, dkk. 2007. Penelitian Tindakan Kelas. Jakarta: Bumi Aksara

Deka Kurnia. 2011. Upaya Meningkatkan Keterampilan Menulis Argumentasi dengan Menggunakan Metode Jigsaw. Skripsi. Tidak diterbitkan. Yogyakarta: Universitas Negeri Yogyakarta.

Dewi Ambarwati. 2011. Peningkatan Keterampilan Menulis Persuasi dengan Media Iklan Advertorial pada Siswa Kelas X SMA Negeri 1 Prembun. Skripsi. Tidak diterbitkan. Yogyakarta: Universitas Negeri Yogyakarta

Keraf, Gorys. 2007. Argumentasi dan narasi. Jakarta: PT Gramedia Pustaka Utama.

Mafrukhi, Wahono, dkk. 2006. Kompeten Berbahasa Indonesia. Jakarta: Erlangga

Medi Yanto. 2013. Penelitian Tindakan Kelas. Yogyakarta: Penerbit Andi.

Munirah. 2007. Dasar Keterampilan Menulis. Tidak diterbitkan. FKIP Universitas Muhammadiyah Makassar.

Munirah. 2010. Model dan Strategi Pembelajaran Bahasa Indonesia. Tidak diterbitkan. Fkip Universitas Muhammadiyah Makassar.

Munirah. 2015. Karya Tulis Ilmiah. Tidak diterbitkan. $\quad$ FKIP Universitas Muhammadiyah Makassar.

Nur, Hanis, dkk. 2001. Keterampilan Dasar Dalam Proses Pembelajaran. Makassar: Penerbit Unismuh Makassar Pers.

Nurgiyantoro, Burhan. 2001. Penilaian Pembelajaran Bahasa. Yogyakarta: Penerbit BPFE 